\title{
Identification of the Constituents of Percutaneous Absorption from Duhaldea nervosa Based on UHPLC-Q-Exactive Orbitrap MS and Microdialysis Technique
}

\author{
Lianghong Liu, ${ }^{1}$ Lian Zhu, ${ }^{1}$ Kaiyan Gong, ${ }^{1}$ Xinjun Zhi, ${ }^{1}$ Ying Guan, ${ }^{1}$ and Wei Cai $\mathbb{D}^{1,2,3}$ \\ ${ }^{1}$ School of Pharmaceutical Sciences, Hunan University of Medicine, Huaihua, China \\ ${ }^{2}$ Hunan Province Key Laboratory for Antibody-Based Drug and Intelligent Delivery System, Hunan University of Medicine, \\ Huaihua, China \\ ${ }^{3}$ Hunan Provincial Key Laboratory of Dong Medicine, Hunan University of Medicine, Huaihua, China
}

Correspondence should be addressed to Wei Cai; 20120941161@bucm.edu.cn

Received 30 June 2019; Accepted 19 October 2019; Published 11 November 2019

Academic Editor: Charles L. Wilkins

Copyright (C) 2019 Lianghong Liu et al. This is an open access article distributed under the Creative Commons Attribution License, which permits unrestricted use, distribution, and reproduction in any medium, provided the original work is properly cited.

\begin{abstract}
Duhaldea nervosa (D. nervosa) has been used for treatment of bone fracture by external use. Thus, the percutaneous absorption was crucial to the effect of $D$. nervosa, especially the constituents of percutaneous absorption. However, the constituents in vivo were never investigated to date. In this study, an efficient method was developed for the identification of constituents of percutaneous absorption using UHPLC-Q-Exactive Orbitrap MS and microdialysis technique. A total of 20 constituents including 15 chlorogenic acid analogues, 3 amino acids, and 2 organic acids were unambiguously or tentatively identified based on highresolution mass data including $\mathrm{MS}$ and $\mathrm{MS}^{2}$, chromatography retention time, and bibliography data. To the best of our knowledge, this is the first study to report the constituents of percutaneous absorption from $D$. nervosa, which will be very helpful for understanding the bioactive compounds and quality control.
\end{abstract}

\section{Introduction}

Duhaldea nervosa (Wallich ex Candolle) A. Anderberg ( $D$. nervosa), which belongs to the plant family Compositae, known as Maoxiucai or Xiaoheiyao in China, is a perennial plant widely distributed in the southwestern region of China and Southeast Asia [1]. Traditionally, it has been used as folk medicine in dispelling wind-chill, alleviating pain, promoting the circulation in meridian and collateral for treating migraine, rheumatism, and traumatic injury, especially in accelerating the healing of a fracture by external use or oral administration $[2,3]$. Previous studies showed that the main constituents of this plant are steroids, terpenes, flavones, and chlorogenic acid analogues, which possess a variety of biological activities including anti-inflammatory activity [4-6].

Considering the usage of $D$. nervosa, which has been used as an external drug for the treatment of bone fracture, the percutaneous absorption was crucial to the effect of $D$. nervosa, especially the constituents of percutaneous absorption [7-9]. As far as we know, the constituent in vivo has not been investigated; therefore, it is worthwhile to identify the constituents of percutaneous absorption after $D$. nervosa for external use.

In recent decades, microdialysis has become a very powerful sampling technique that enables monitoring of the small molecules in vivo due to its excellent versatility $[10,11]$. However, it is limited by the method of analyzing the resulting dialysate. LC-MS as a new technique was used to analyze and identify the constituent in extract botanical and biological sample including dialysate. Among all exiting platforms, ultra-high performance liquid chromatography (UHPLC) coupled with high resolution mass spectrometry (HRMS), including UHPLC-Q-TOF MS, UHPLC LTQOrbitrap MS, and UHPLC Q-Exactive Orbitrap MS, is the most powerful technique for the detection and identification 
of constituents, as UHPLC can provide a fast and effective separation while HRMS can provide accurate mass measurement and fragment ion, which will be very much beneficial for structure elucidation [12-14].

The present study was designed to detect and identify the main constituents of percutaneous absorption from $D$. nervosa by UHPLC-Q-Exactive Orbitrap MS and microdialysis. Finally, a total of 20 constituents including 15 chlorogenic acid analogues, 3 amino acids, and 2 organic acids were detected and identified based on high-resolution mass data including MS and $\mathrm{MS}^{2}$, chromatography retention time, and bibliography data. To the best of our knowledge, this is the first study to report the constituents of percutaneous absorption from $D$. nervosa, which will be very helpful for understanding the bioactive compounds and quality control.

\section{Material and Methods}

2.1. Chemicals and Materials. Acetonitrile and formic acid of LC-MS grade and methanol of LC grade were obtained from Aladdin Industrial Corporation. The ultrapure water used throughout the experiment was purified by a Milli-Q water purification system (Millipore, Milford, MA, United States). Other reagents of analytical grade were obtained from Aladdin Industrial Corporation.

The reference standards of 3-caffeoylquinic acid (3CQA, neochlorogenic acid, X-014-170309), 4-caffeoylquinic acid (4-CQA, cryptochlorogenic acid, Y-067-180425), 5caffeoylquinic acid (5-CQA, CGA, L-007-171216), 3,5dicaffeoylquinic acid (3,5-DiCQA, isochlorogenic acid A, Y-068-170903), 3,4-dicaffeoylquinic acid (3,4-DiCQA, isochlorogenic acid B, Y-069-180105), and 4,5-dicaffeoylquinic acid (4,5-DiCQA, isochlorogenic acid C, Y-070-170515) were purchased from ChengDu Herbpurify Co., Ltd. (ChengDu, China). The purities of all reference standards were no less than $98 \%$ based on HPLC-UV analysis.

2.2. Sample Preparation. The root of $D$. nervosa was extracted by reflux with about eightfold $50 \%$ ethanol at $70^{\circ} \mathrm{C}$ for two hours. Then, the filtrate extracts were concentrated under reduced pressure to yield a black residue. Finally, the residue was redissolved in 50\% ethanol to give a sample with a concentration of $0.5 \mathrm{~g} / \mathrm{mL}$.

2.3. Animal Experiments. All in vivo microdialysis were performed with CMA 402 syringe pump and MAB 85 refrigerated fraction collector (CMA, Microdialysis AB, Sweden). Four male SD rats (weighing 150-200 g, Hunan SJA Laboratory Animal Company, China) were used in in vivo study. All procedures were performed under the conditions of National Act on the Use of Experimental Animals. Anesthesia was induced by an intraperitoneal injection of $1.2 \mathrm{~mL} / 100 \mathrm{~g}$ $20 \%$ urethane before each experiment. The leg of the rat was shaved carefully with razor without breaking the cuticle. After shaving, the rats were placed on an animal heat insulator. Body temperature was kept at $36-38^{\circ} \mathrm{C}$. A CMA 20 Elite microdialysis probe $(4 \mathrm{~mm}$, polyarylethersulfone membrane,
MWCO of $20 \mathrm{kDa}$ ) was then inserted into the dermis after fixing the introducer needle, parallel to the skin on the leg. Probe was perfused with normal saline before the insertion. The inlet and outlet were sealed to keep air from entering the probes.

The probes were perfused with normal saline at a flow rate of $2.0 \mu \mathrm{L} / \mathrm{min}$. A $60 \mathrm{~min}$ blank dialysate sample was collected for release of the insertion microtrauma prior to the application of D. nervosa. Then, a dosage of $5 \mathrm{~g} / \mathrm{mL}$ of the material was applied to an area of $2.0 \times 3.0 \mathrm{~cm}^{2}$ and covered with gauze and bandages. Microdialysate samples were obtained every $60 \mathrm{~min}$ up to $10 \mathrm{~h}$, which was combined into one sample for each rat. During sampling, the microdialysis vials were cooled to $4^{\circ} \mathrm{C}$; afterward, they were stored at $-80^{\circ} \mathrm{C}$ until analysis.

2.4. Sample Pretreatment. All the microdialysates were pretreated by a solid-phase extraction (SPE) method. A SPE column (WondaSep C18, $200 \mathrm{mg} / 3 \mathrm{~mL}$ ) was activated and equilibrated with $6 \mathrm{~mL}$ of methanol and $6 \mathrm{~mL}$ of water containing $0.5 \%$ formic acid, successively. A total of $1 \mathrm{~mL}$ microdialysate was loaded on the column. Then, the column was washed by $3 \mathrm{~mL}$ of water containing $0.5 \%$ formic acid and $3 \mathrm{~mL}$ of methanol, respectively. The methanol elute was collected and concentrated under $\mathrm{N}_{2}$ at room temperature to gain residue, which was redissolved in $100 \mu \mathrm{L}$ of acetronitrile-water $(1: 1, \mathrm{v} / \mathrm{v})$ and centrifuged at $12000 \mathrm{rpm}$ for $30 \mathrm{~min}$ at $4^{\circ} \mathrm{C}$. Finally, an aliquot of $5 \mu \mathrm{L}$ supernatant was injected into the UHPLC-Q-Excative Orbitrap MS.

2.5. Instruments and Conditions. An Ultimate 3000 focused (Dionex, Sunnyvale, CA, USA) system equipped with an online vacuum degasser, a quaternary pump, and an auto sampler was used for UHPLC analysis. Separation was performed on an HYPERSIL GOLD C18 column $(100 \times 2.1 \mathrm{~mm}, 1.9 \mu \mathrm{m})$ at $35^{\circ} \mathrm{C}$. The mobile phase consisted of water containing $0.1 \%$ formic acid (A) and acetonitrile (B) using a gradient elution at a flow rate of $0.3 \mathrm{~mL} / \mathrm{min}$. The flowing gradient was applied: $5 \%-10 \% \mathrm{~B}$ at $0-2 \mathrm{~min}$; $10 \%-20 \% \mathrm{~B}$ at $2-5 \mathrm{~min} ; 20 \%-25 \% \mathrm{~B}$ at $5-10 \mathrm{~min} ; 25 \%-55 \%$ $\mathrm{B}$ at $10-12 \mathrm{~min} ; 55 \%-80 \% \mathrm{~B}$ at $12-15 \mathrm{~min} ; 80 \%-5 \% \mathrm{~B}$ at $15-16 \mathrm{~min}$; and $5 \% \mathrm{~B}$ at $16-20 \mathrm{~min}$.

All ESI-MS ${ }^{n}$ analyses were carried out on a Q-Exactive Focus Orbitrap MS (Thermo Electron, Bremen, Germany) coupled with a heated electrospray ionization source (Thermo Electron, Bremen, Germany) in the negative mode. The tune operating parameters were as follows: the rate of sheath gas flow and auxiliary gas flow was 30 and 10 (arbitrary unit), respectively; spray voltage, $3.0 \mathrm{kV}$; the temperature of capillary and auxiliary gas heater was $320^{\circ} \mathrm{C}$ and $350^{\circ} \mathrm{C}$, respectively; high-resolution $\mathrm{MS}^{n}$ was operated at full scan with a mass range of $\mathrm{m} / \mathrm{z} 100-1200$ at a resolution of 35000 and $\mathrm{MS}^{2}$ at a resolution of 17500 triggered by data-dependent $\mathrm{MS}^{n}$ scanning; nitrogen served as collision gas; and the energy was set as normalized collision energy $30 \%$. 
TABLE 1: The retention time and mass spectrometric data of constituents of percutaneous absorption.

\begin{tabular}{|c|c|c|c|c|c|c|c|}
\hline Peak & $t_{\mathrm{R}}$ & $\begin{array}{l}\text { Theoretical } \\
\text { mass }\end{array}$ & $\begin{array}{l}\text { Experimental } \\
\text { mass }\end{array}$ & Error & $\begin{array}{l}\text { Formula } \\
{[\mathrm{M}-\mathrm{H}]^{-}}\end{array}$ & Fragment & Identification \\
\hline 1 & 0.96 & 133.01425 & 133.01361 & -4.78 & $\mathrm{C}_{4} \mathrm{H}_{5} \mathrm{O}_{5}$ & $\begin{array}{c}\mathrm{MS}^{2} \text { [133]: } 115.0026(100), 71.0131 \text { (42), } \\
89.0235(8)\end{array}$ & Malic acid isomer \\
\hline 2 & 1.11 & 133.01425 & 133.01365 & -4.49 & $\mathrm{C}_{4} \mathrm{H}_{5} \mathrm{O}_{5}$ & 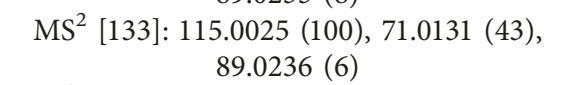 & Malic acid isomer \\
\hline 3 & 3.15 & 353.08781 & 353.08743 & -1.06 & $\mathrm{C}_{16} \mathrm{H}_{17} \mathrm{O}_{9}$ & $\begin{array}{c}\mathrm{MS}^{2} \text { [353]: } 191.0547(100), 179.0336(76), \\
135.0436(21)\end{array}$ & 3-CQA \\
\hline 4 & 3.45 & 203.08260 & 203.08188 & -3.55 & $\mathrm{C}_{11} \mathrm{H}_{11} \mathrm{O}_{2} \mathrm{~N}_{2}$ & $\begin{array}{c}\mathrm{MS}^{2} \text { [203]: } 116.0492(100), 74.0233(38) \\
142.0650(27), 159.0918(21)\end{array}$ & Tryptophan \\
\hline 5 & 4.12 & 337.09289 & 337.09323 & 1.01 & $\mathrm{C}_{16} \mathrm{H}_{17} \mathrm{O}_{8}$ & $\begin{array}{c}\mathrm{MS}^{2} \text { [337]: } 163.0389(55), 119.0489(20), \\
191.0552(9)\end{array}$ & 3-pCoQA \\
\hline 6 & 4.50 & 353.08781 & 353.08771 & -0.27 & $\mathrm{C}_{16} \mathrm{H}_{17} \mathrm{O}_{9}$ & $\mathrm{MS}^{2}[353]: 191.0547(100)$ & 5-CQA \\
\hline 7 & 4.67 & 353.08781 & 353.08780 & 2 & $\mathrm{C}_{16} \mathrm{H}_{17} \mathrm{O}_{9}$ & $\begin{array}{c}\mathrm{MS}^{2} \text { [353]: } 173.0441(100), 179.0336(82), \\
191.0547(52), 135.0435(30)\end{array}$ & 4-CQA \\
\hline 8 & 4.70 & 367.10345 & 367.10306 & -1.08 & $\mathrm{C}_{17} \mathrm{H}_{19} \mathrm{O}_{9}$ & $\mathrm{MS}^{2}$ [367]: 193.0497 (100), 134.0361 (18) & 3-FQA \\
\hline 9 & 5.37 & 353.08781 & 353.08783 & 0.07 & $\mathrm{C}_{16} \mathrm{H}_{17} \mathrm{O}_{9}$ & $\begin{array}{c}\mathrm{MS}^{2} \text { [353]: } 191.0548(100), 135.0435(4) \\
\text { 179.0334 (3), } 173.0078(3)\end{array}$ & Cis-5-CQA \\
\hline 10 & 5.59 & 337.09289 & 337.09302 & 0.38 & $\mathrm{C}_{16} \mathrm{H}_{17} \mathrm{O}_{8}$ & $\begin{array}{c}\mathrm{MS}^{2} \text { [337]: } 191.0552(100), 173.0445(10), \\
163.0390(8)\end{array}$ & $5-p \operatorname{CoQA}$ \\
\hline 11 & 5.69 & 515.11950 & 515.11969 & 0.37 & $\mathrm{C}_{25} \mathrm{H}_{23} \mathrm{O}_{12}$ & $\begin{array}{c}\mathrm{MS}^{2} \text { [515]: } 191.0545(100), 179.0333(88) \\
353.0860(16), 135.0434(13)\end{array}$ & 1,3-DiCQA \\
\hline 12 & 5.70 & 172.0 & 172.09697 & -5.50 & $\mathrm{C}_{8} \mathrm{H}_{15} \mathrm{NO}_{3}$ & $\mathrm{MS}^{2}[172]: 130.0861(100)$ & $N$-Acetyl-leucine \\
\hline 13 & 6.07 & 172.09792 & 172.09691 & -5.85 & $\mathrm{C}_{8} \mathrm{H}_{15} \mathrm{NO}_{3}$ & $\mathrm{MS}^{2}[172]: 130.0861(100)$ & \\
\hline 14 & 6.13 & 367.10345 & 367.10355 & 0.26 & $\mathrm{C}_{17} \mathrm{H}_{19} \mathrm{O}_{9}$ & $\begin{array}{c}\mathrm{MS}^{2} \text { [367]: } 173.0445(100), 93.0331(88), \\
191.0552(47)\end{array}$ & 4-FQA \\
\hline 15 & 6.31 & 337.09289 & 337.09286 & -0.09 & $\mathrm{C}_{16} \mathrm{H}_{17} \mathrm{O}_{8}$ & $\mathrm{MS}^{2}$ [337]: $173.0445(100)$ & 4-pCoQA \\
\hline 16 & 6.64 & 367.10345 & 367.10294 & -1.40 & $\mathrm{C}_{17} \mathrm{H}_{19} \mathrm{O}_{9}$ & $\operatorname{MS}^{2}$ [367]: $191.0547(100)$ & 5-FQA \\
\hline 17 & 7.69 & 515.11950 & 515.11981 & 0.60 & $\mathrm{C}_{25} \mathrm{H}_{23} \mathrm{O}_{12}$ & $\begin{array}{c}\mathrm{MS}^{2}[515]: 173.0441(100), 179.0335(89) \\
191.0547 \text { (34), } 135.0435(14), 353.0865(14)\end{array}$ & 3,4-DiCQA \\
\hline 18 & 7.85 & 515.11950 & 515.11938 & -0.23 & $\mathrm{C}_{25} \mathrm{H}_{23} \mathrm{O}_{12}$ & $\begin{array}{c}\mathrm{MS}^{2}[515]: 191.0546(100), 179.0335(62) \\
353.0865(15), 135.0435(11)\end{array}$ & 3,5-DiCQA \\
\hline 19 & 8.16 & 515.11950 & 515.11920 & -0.58 & $\mathrm{C}_{25} \mathrm{H}_{23} \mathrm{O}_{12}$ & $\begin{array}{l}\mathrm{MS}^{2}[515]: 191.0546(100), 179.0335(72) \\
353.0865 \text { (18), } 173.0445(11), 135.0435(11)\end{array}$ & 1,5-DiCQA \\
\hline 20 & 8.62 & 515.11950 & 515.11902 & -0.93 & $\mathrm{C}_{25} \mathrm{H}_{23} \mathrm{O}_{12}$ & $\begin{array}{l}\mathrm{MS}^{2}[515]: 173.0445(100), 179.0340(71) \\
191.0552(25), 353.0865(22), 135.0439\end{array}$ & 4,5-DiCQA \\
\hline
\end{tabular}

2.6. Data Processing and Analysis. The Xcalibur software version 4, (Thermo Fisher Scientific, San Jose, CA, USA) was used to acquire the raw data including the full-scan MS and $\mathrm{MS}^{2}$ data, which were processed by the Compound Discover version 3 using the metabolomics workflow templates to detect the differential components between the microdialysates before and after application of $D$. nervosa. The detailed parameters of metabolomics workflow template were as follows: The minimum peak intensity was set as 10000; the maximum element counts were $\mathrm{C} 30 \mathrm{H} 60 \mathrm{O} 20 \mathrm{~S} 4 \mathrm{~N} 10 \mathrm{Cl}$; the mass tolerance of $\mathrm{MS}$ and $\mathrm{MS}^{2}$ was within 5 and $10 \mathrm{ppm}$, respectively; and differential analysis was selected for postprocessing.

\section{Results and Discussion}

3.1. Identification of Percutaneous Absorption Constituents of D. nervosa. A total of 20 constituents were detected and identified based on UHPLC-Q-Exactive Orbitrap MS and microdialysis technique. The retention time and mass spectrometric data of those constituents are listed in Table 1. The high-resolution extracted ion chromatography of those compounds is shown in Figure 1.
3.2. Identification of Chlorogenic Acid Analogues. Compounds 3, $6,7,17,18$, and 20 with the pseudomolecular ion $[\mathrm{M}-\mathrm{H}]^{-}$of $\mathrm{m} / \mathrm{z} \quad 353.08783 \quad\left(0.07 \mathrm{ppm}, \quad \mathrm{C}_{16} \mathrm{H}_{17} \mathrm{O}_{9}\right), \quad 353.08771$ (-0.27 ppm, $\mathrm{C}_{16} \mathrm{H}_{17} \mathrm{O}_{9}$ ), 353.08780 (-0.02 ppm, $\mathrm{C}_{16} \mathrm{H}_{17} \mathrm{O}_{9}$ ), 515.11981 (0.60 ppm, $\left.\mathrm{C}_{25} \mathrm{H}_{23} \mathrm{O}_{12}\right), 515.11938$ (-0.23 ppm, $\left.\mathrm{C}_{25} \mathrm{H}_{23} \mathrm{O}_{12}\right)$, and $515.11902\left(-0.93 \mathrm{ppm}, \mathrm{C}_{25} \mathrm{H}_{23} \mathrm{O}_{12}\right)$, respectively, were accurately identified as tran-3-CQA, tran-5CQA, tran-4-CQA, 3,4-DiCQA, 3,5-DiCQA, and 4,5DiCQA by comparing their chromatography retention times, accurate mass measurement, and fragment pattern with those data of reference compounds.

Compounds 9, 11, and 19 were eluted at 5.37, 5.69, and $8.16 \mathrm{~min}$, respectively, with the deprotonation ion $[\mathrm{M}-\mathrm{H}]^{-}$of $\mathrm{m} /$ z 353.08783 (0.07 ppm, $\left.\mathrm{C}_{16} \mathrm{H}_{17} \mathrm{O}_{9}\right), 515.11969$ (0.37 ppm, $\mathrm{C}_{25} \mathrm{H}_{23} \mathrm{O}_{12}$ ), and 515.11920 (-0.58 ppm, $\mathrm{C}_{25} \mathrm{H}_{23} \mathrm{O}_{12}$ ), suggesting that those are isomer of compounds 3, 6, 7 and 17, 18, 20, respectively, which were confirmed by the $\mathrm{MS}^{2}$ spectrum. Finally, those were tentatively characterized as cis-5-CQA, 1,3DiCQA, and 1,5-DiCQA according to the literature data $[15,16]$. Compounds 5,10 , and 15 possessing a $[\mathrm{M}-\mathrm{H}]^{-}$ion of $\mathrm{m} / \mathrm{z} 337.09323$ (1.01 ppm, $\left.\mathrm{C}_{16} \mathrm{H}_{17} \mathrm{O}_{8}\right), 337.09302$ (0.38 ppm, $\mathrm{C}_{16} \mathrm{H}_{17} \mathrm{O}_{8}$ ), and $337.09286\left(-0.09 \mathrm{ppm}, \mathrm{C}_{16} \mathrm{H}_{17} \mathrm{O}_{8}\right)$, respectively, 


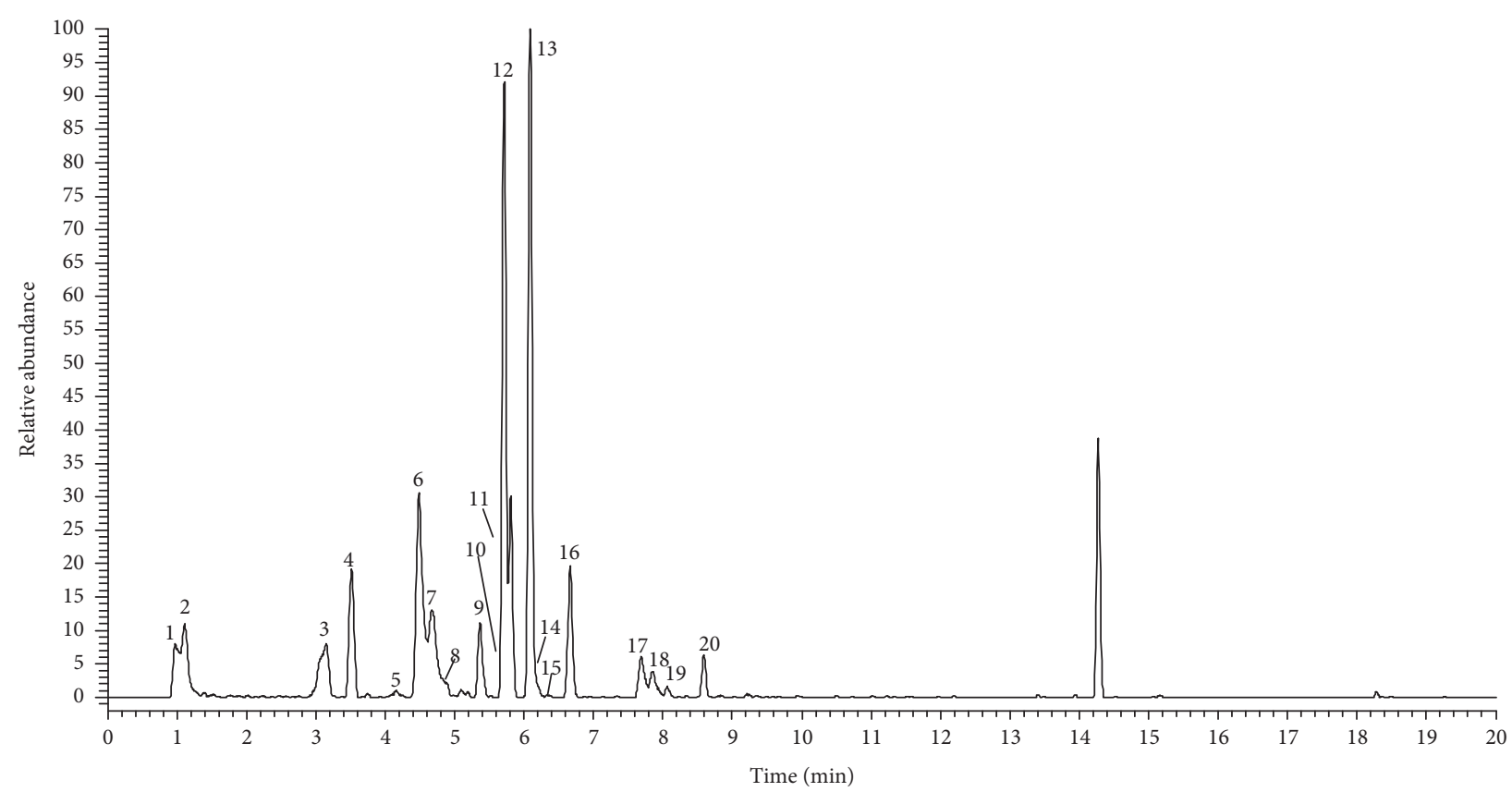

FiguRE 1: The high-resolution extracted ion chromatography of multiple constituents at $\mathrm{m} / \mathrm{z} 133.01425,172.09792,203.08260,337.09289$, 353.08781, 367.10345, and 515.11950.

were eluted at 4.12, 5.59, and $6.31 \mathrm{~min}$, respectively, suggesting that they were $p$-coumaroylquinic acid ( $p$ CoQA). Considering the base peak at $\mathrm{m} / \mathrm{z} 163.0389,191.0552$, and 173.0445 of the precursor ion at $\mathrm{m} / \mathrm{z} 337[17,18]$, they were tentatively presumed to be 3-pCoQA, 5- $p$ CoQA, and 4- $p$ CoQA, respectively.

Compounds 8, 14, and 16 eluted at 4.70, 6.13, and $6.64 \mathrm{~min}$, respectively. All of them showed a pseudomolecular ion $[\mathrm{M}-\mathrm{H}]^{-}$of $\mathrm{m} / \mathrm{z} 367.10306 \quad(-1.08 \mathrm{ppm}$, $\left.\mathrm{C}_{17} \mathrm{H}_{19} \mathrm{O}_{9}\right), 367.10355$ (0.26 ppm, $\left.\mathrm{C}_{17} \mathrm{H}_{19} \mathrm{O}_{9}\right)$, and 367.10294 $\left(-1.40 \mathrm{ppm}, \mathrm{C}_{17} \mathrm{H}_{19} \mathrm{O}_{9}\right)$, respectively. The base peak at 193.0497, 173.0445, and 191.0547 in $\mathrm{MS}^{2}$ spectrum were used to discriminate isomers of feruloylquinic acid (FQA) $[17,18]$; therefore, they were tentatively inferred to be 3FQA, 4-FQA, and 5-FQA, respectively.

3.3. Identification of Amino Acid. Compounds 4, 12, and 13 were detected at $3.45,5.70$, and $6.07 \mathrm{~min}$ with the $[\mathrm{M}-\mathrm{H}]^{-}$ ion at $\mathrm{m} / \mathrm{z} 203.08181\left(-3.55 \mathrm{ppm}, \mathrm{C}_{11} \mathrm{H}_{11} \mathrm{O}_{2} \mathrm{~N}_{2}\right), 172.09697$ (-5.05 ppm, $\left.\mathrm{C}_{8} \mathrm{H}_{14} \mathrm{O}_{3} \mathrm{~N}\right)$, and 172.09691 (-5.85 ppm, $\left.\mathrm{C}_{8} \mathrm{H}_{14} \mathrm{O}_{3} \mathrm{~N}\right)$, respectively. The $\mathrm{MS}^{2}$ spectrum was used to elucidate the structure by searching various MS/MS databases including massbank, METLIN, and KEGG [19]. Therefore, they were temporarily determined to be tryptophan, N-acetyl-leucine, and N-acetyl-alloisoleucine, respectively.

3.4. Identification of Organic Acid. Compounds 1 and 2 with the same pseudomolecular ion $[\mathrm{M}-\mathrm{H}]^{-}$of $\mathrm{m} / \mathrm{z} 133.014$ $\left(\mathrm{C}_{4} \mathrm{H}_{5} \mathrm{O}_{5}\right)$ were detected at 0.96 and $1.11 \mathrm{~min}$, respectively. The fragment ion at $115.0026\left(-9.4 \mathrm{ppm}, \mathrm{C}_{4} \mathrm{H}_{3} \mathrm{O}_{4}\right), 71.0131$ $\left(-10.6 \mathrm{ppm}, \mathrm{C}_{3} \mathrm{H}_{3} \mathrm{O}_{2}\right)$ and 89.0235 (-10.3 ppm, $\left.\mathrm{C}_{3} \mathrm{H}_{5} \mathrm{O}_{3}\right)$ was detected in $\mathrm{MS}^{2}$ spectrum by natural loss of $\mathrm{H}_{2} \mathrm{O}, \mathrm{CH}_{2} \mathrm{O}_{3}$, and $\mathrm{CO}_{2}$, suggesting the presence of carboxyl and hydroxyl. According to the literature [20], they were temporarily identified as malic acid isomers.

\section{Conclusion}

The constituents of percutaneous absorption following the external use of $D$. nervosa were investigated using UHPLCQ-Exactive Orbitrap MS and microdialysis technique. Finally, a total of 20 constituents including 15 chlorogenic acid analogues, 3 amino acids, and 2 organic acids were detected and identified based on high-resolution mass data including $\mathrm{MS}$ and $\mathrm{MS}^{2}$, chromatography retention time, and bibliography data. To our best knowledge, this is the first study to investigate the constituents of percutaneous absorption from $D$. nervosa, which will be very beneficial for understanding the bioactive compounds and quality control.

\section{Data Availability}

The data used to support the finding of this study are available from the corresponding author upon request.

\section{Disclosure}

This work was presented as an oral presentation at Consortium for Globalization of Chinese Medicine (CGCM2019) in Shanghai.

\section{Conflicts of Interest}

The authors have declared no conflicts of interest. 


\section{Authors' Contributions}

Lianghong Liu and Lian Zhu contributed equally to this work.

\section{Acknowledgments}

This work was financially supported by the National Natural Science Foundation of China (no. 81603393), the Natural Science Foundation of Hunan Province (no. 2018JJ3376), the Scientific Research Fund of Hunan Provincial Education Department (no. 16B185), and Hunan University of Medicine High-Level Talent Introduction Startup Funds (no. 15001).

\section{References}

[1] C. W. Xiao, Explore Secret of Dong Medicine, Yuelu Press, Changsha, China, 2004.

[2] C. W. Xiao, "Textual research of dong medicine and a famous doctor for treating traumatic injury," Journal of Medicine \& Pharmacy of Chinese Minorities, vol. 5, pp. 41-42, 1997.

[3] S. Long, "Clinical experience of "maoshoucai" for treating traumatic injury," Journal of Medicine \& Pharmacy of Chinese Minorities, vol. 12, pp. 231-232, 2004.

[4] L. Yan, Y. Huang, J.-J. Fu et al., "Three new phenylpropanoids from inula nervosaWall," Helvetica Chimica Acta, vol. 93, no. 7, pp. 1418-1421, 2010.

[5] L. Yan, X. R. Cheng, Q. Zeng, J. J. Qin, W. D. Zhang, and H. Z. Jin, "Phytane and neoclerodane diterpenes from the aerial parts of Inula nervosa Wall," Biochemical Systematics and Ecology, vol. 39, no. 4-6, pp. 700-703, 2011.

[6] Y. Guan, Y. Wang, Y. Zhou et al., "Determination of isochlorogenic acid A and isochlorogenic acid C in Duhaldea nervosa by HPLC," Lishizhen Medicine and Materia Medica Research, vol. 28, no. 5, pp. 1032-1034, 2017.

[7] V. Sarikaki, M. Rallis, H. Tanojo et al., "In vitro percutaneous absorption of pine bark extract (Pycnogenol) in human skin," Journal of Toxicology: Cutaneous and Ocular Toxicology, vol. 23, no. 3, pp. 149-158, 2005.

[8] L. Chen, L. Han, O. Saib, and G. Lian, "In silico prediction of percutaneous absorption and disposition kinetics of chemicals," Pharmaceutical Research, vol. 32, no. 5, pp. 1779-1793, 2015.

[9] H. Yoshimatsu, K. Ishii, Y. Konno, M. Satsukawa, and S. Yamashita, "Prediction of human percutaneous absorption from in vitro and in vivo animal experiments," International Journal of Pharmaceutics, vol. 534, no. 1-2, pp. 348-355, 2017.

[10] R. A. Saylor and S. M. Lunte, "A review of microdialysis coupled to microchip electrophoresis for monitoring biological events," Journal of Chromatography A, vol. 1382, pp. $48-64,2015$.

[11] A. G. Zestos and R. T. Kennedy, "Microdialysis coupled with LC-MS/MS for in vivo neurochemical monitoring," The AAPS Journal, vol. 19, no. 5, pp. 1284-1293, 2017.

[12] X. Qiao, R. Li, W. Song et al., "A targeted strategy to analyze untargeted mass spectral data: rapid chemical profiling of Scutellaria baicalensis using ultra-high performance liquid chromatography coupled with hybrid quadrupole orbitrap mass spectrometry and key ion filtering," Journal of Chromatography A, vol. 1441, no. 8, pp. 83-95, 2016.

[13] W. Yang, X. Qiao, K. Li et al., "Identification and differentiation of Panax ginseng, Panax quinquefolium, and Panax notoginseng by monitoring multiple diagnostic chemical markers," Acta Pharmaceutica Sinica B, vol. 6, no. 6, pp. 568-575, 2016.

[14] W. Cai, Y. Guan, Y. Zhou, Y. Wang, H. Ji, and Z. Liu, "Detection and characterization of the metabolites of rutaecarpine in rats based on ultra-high-performance liquid chromatography with linear ion trap-orbitrap mass spectrometer," Pharmaceutical Biology, vol. 55, no. 1, pp. 294-298, 2017.

[15] M. N. Clifford, K. L. Johnston, S. Knight, and N. Kuhnert, "Hierarchical scheme for LC-msnidentification of chlorogenic acids," Journal of Agricultural and Food Chemistry, vol. 51, no. 10, pp. 2900-2911, 2003.

[16] L. Liu, J. Zhang, B. Zheng et al., "Rapid characterization of chlorogenic acids in Duhaldea nervosa based on ultra-highperformance liquid chromatography-linear trap quadropoleorbitrap-mass spectrometry and mass spectral trees similarity filter technique," Journal of Separation Science, vol. 41, no. 8, pp. 1764-1774, 2018.

[17] M. N. Clifford, S. Marks, S. Knight, and N. Kuhnert, "Characterization by LC-msnof four new classes of p-coumaric acid-containing diacyl chlorogenic acids in green coffee beans," Journal of Agricultural and Food Chemistry, vol. 54, no. 12 , pp. 4095-4101, 2006.

[18] M. N. Clifford, W. Wu, J. Kirkpatrick, and N. Kuhnert, "Profiling the chlorogenic acids and other caffeic acid derivatives of herbal Chrysanthemum by LC-MSn," Journal of Agricultural and Food Chemistry, vol. 55, no. 3, pp. 929-936, 2007.

[19] C. Guijas, J. R. Montenegro-Burke, X. Domingo-Almenara et al., "METLIN: a technology platform for identifying knowns and unknowns," Analytical Chemistry, vol. 90, no. 5, pp. 3156-3164, 2018.

[20] A. Ertas, M. A. Yilmaz, and M. Firat, "Chemical profile by LCMS/MS, GC/MS and antioxidant activities of the essential oils and crude extracts of two Euphorbiaspecies," Natural Product Research, vol. 29, no. 6, pp. 529-534, 2015. 

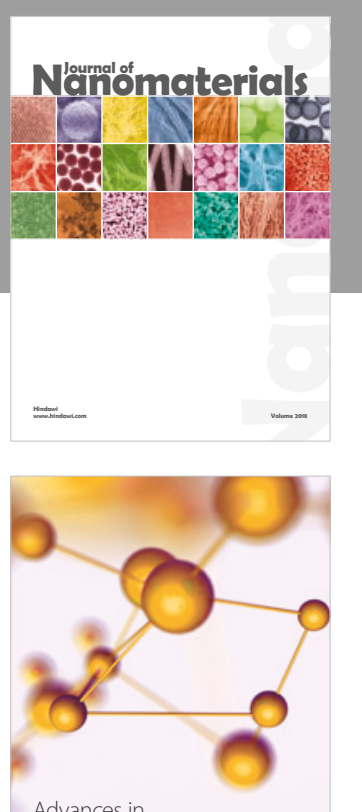

Physical Chemistry
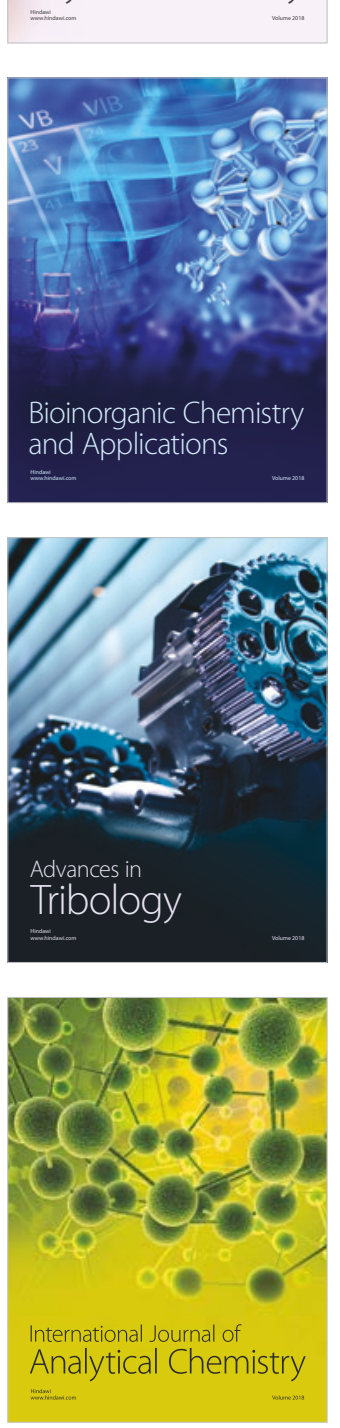

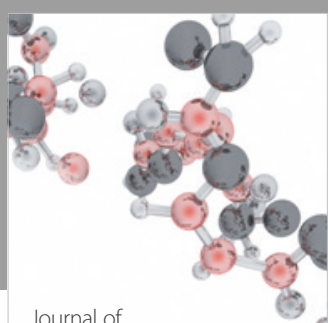

Analytical Methods

in Chemistry

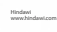

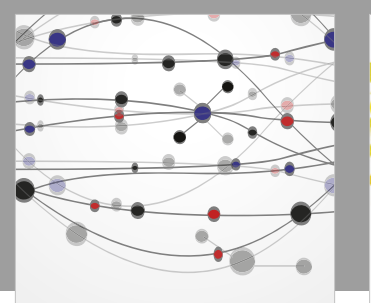

The Scientific World Journal

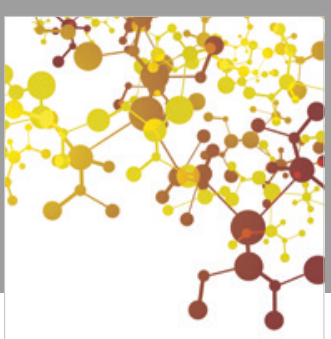

Journal of

Applied Chemistry
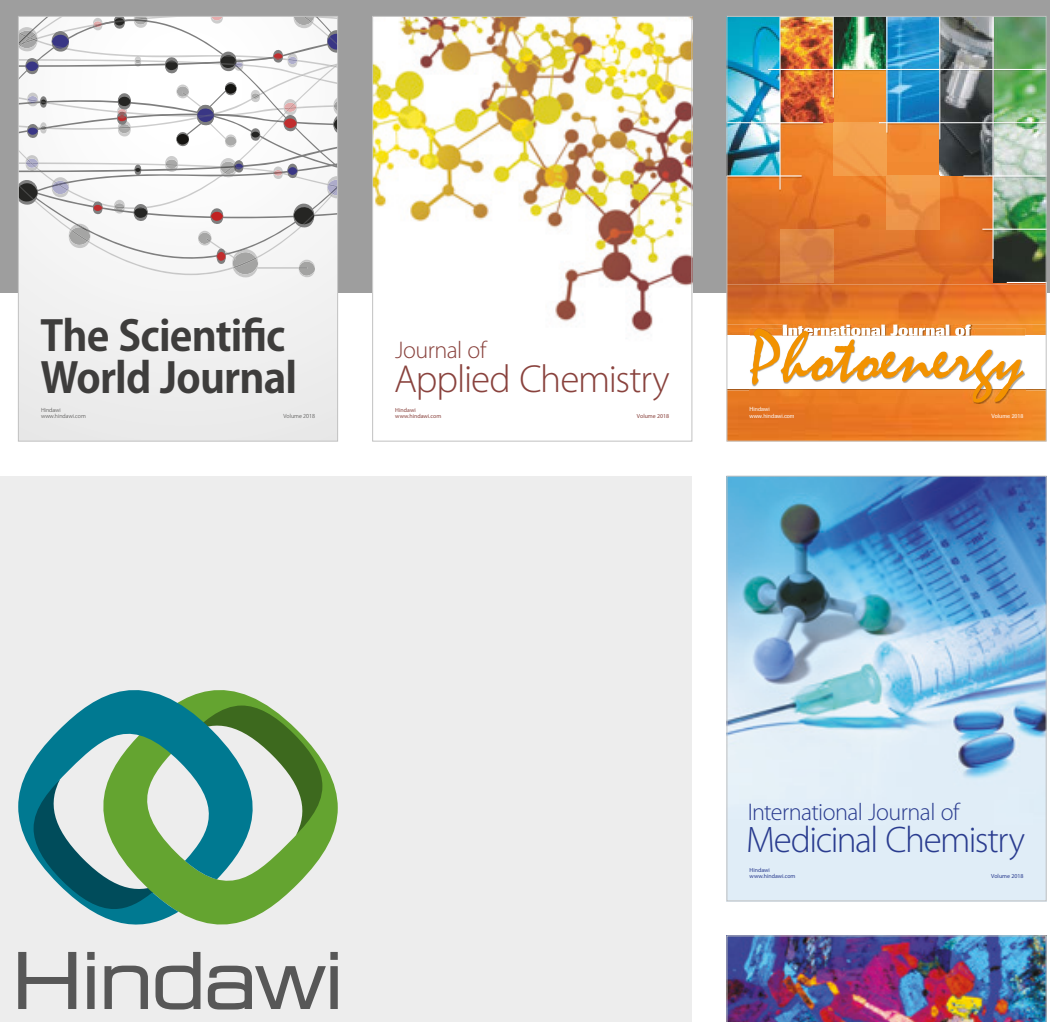

Submit your manuscripts at

www.hindawi.com
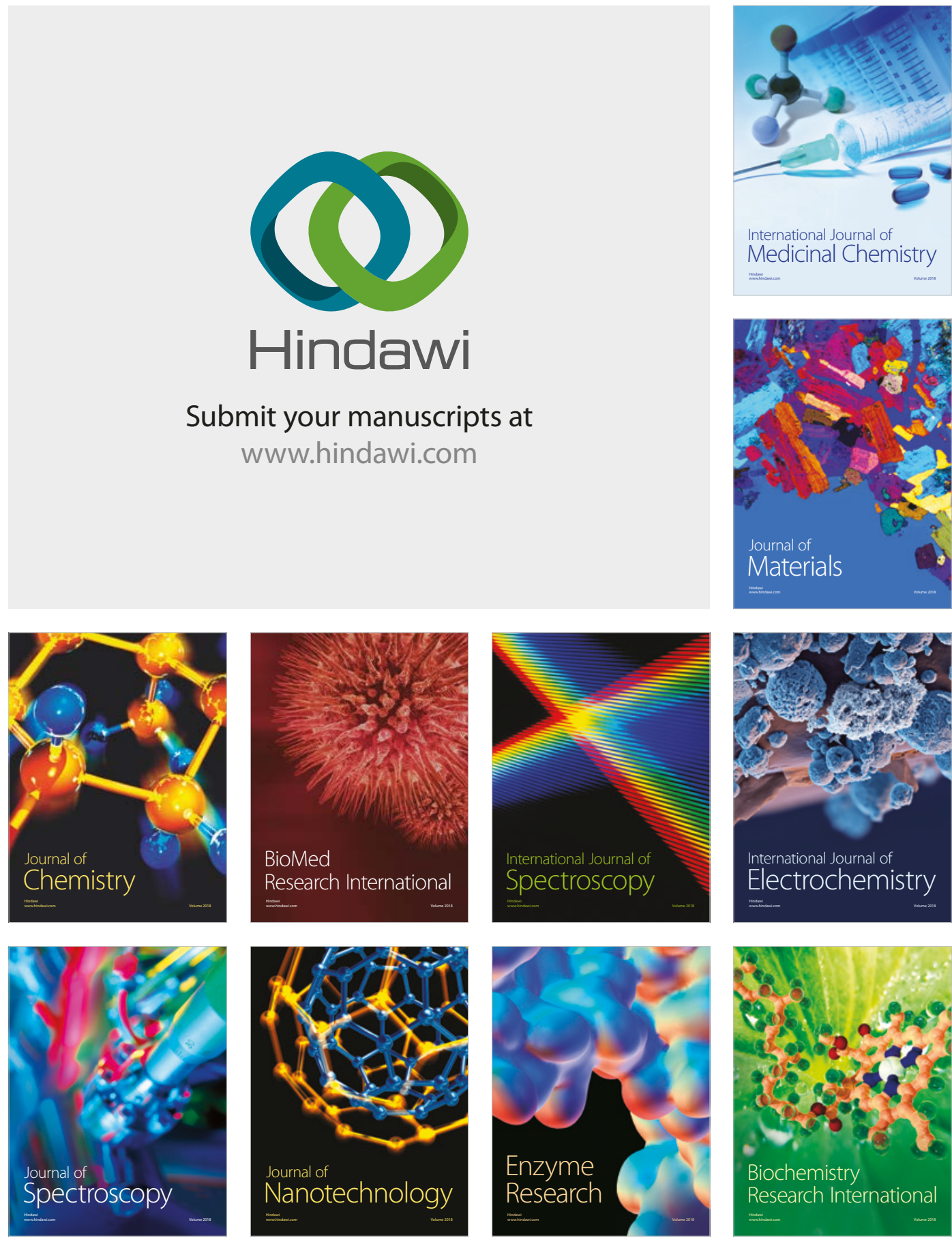
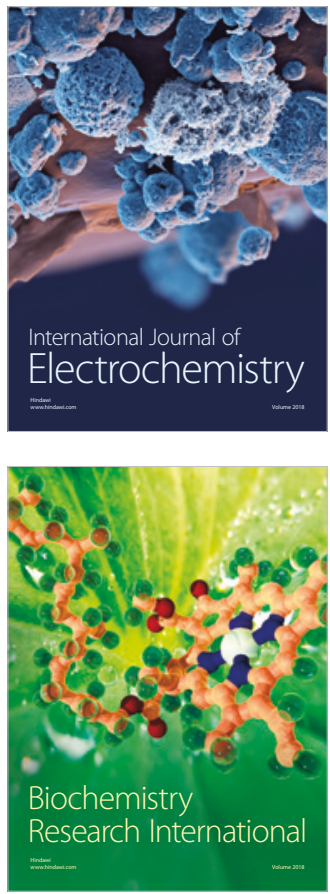